\title{
Atrioventricular valve regurgitation in patients undergoing total cavopulmonary connection: Impact of valve morphology and underlying mechanisms on survival and reintervention
}

\author{
Masamichi Ono, MD, PhD, ${ }^{\mathrm{a}}$ Julie Cleuziou, MD, ${ }^{\mathrm{a}}$ Jelena Pabst von Ohain, $\mathrm{MD}, \mathrm{PhD},{ }^{\mathrm{a}}$ \\ Elisabeth Beran, MD, ${ }^{\mathrm{a}}$ Melchior Burri, MD, ${ }^{\mathrm{a}}$ Martina Strbad, MS, ${ }^{\mathrm{a}}$ Alfred Hager, MD, \\ Jürgen Hörer, $\mathrm{MD}, \mathrm{PhD},{ }^{\mathrm{c}}$ Christian Schreiber, $\mathrm{MD}, \mathrm{PhD},{ }^{\mathrm{a} \dagger}$ and Rüdiger Lange $\mathrm{MD}, \mathrm{PhD}^{\mathrm{a}, \mathrm{d}}$
}

\section{ABSTRACT}

Objective: The study objective was to determine the mechanisms of atrioventricular valve regurgitation in single-ventricle physiology and their influence on outcomes after total cavopulmonary connection.

Methods: Among 460 patients who underwent a total cavopulmonary connection, $101(22 \%)$ had atrioventricular valve surgery before or coincident with total cavopulmonary connection.

Results: Atrioventricular valve morphology showed 2 separated in 33 patients, mitral in 11 patients, tricuspid in 41 patients, and common in 16 patients. Patients with a tricuspid and a common atrioventricular valve underwent atrioventricular valve surgery frequently, $27 \%$ and $36 \%$, respectively. Atrioventricular valve regurgitation was due to 1 or more of the following mechanisms: dysplastic leaflet (62), prolapse (53), annular dilation (27), cleft (22), and chordal anomaly (14). Structural anomalies were observed in 89 patients $(88 \%)$. The procedure was atrioventricular valve repair in 81 patients, atrioventricular valve closure in 16 patients, and atrioventricular valve replacement in 4 patients. Among 81 patients who underwent initial repair, repeat repair was required in 20 patients, atrioventricular valve replacement was required in 7 patients, and atrioventricular valve closure was required in 3 patients. Among patients undergoing atrioventricular valve surgery, overall survival after total cavopulmonary connection $(88 \%$ vs $95 \%$ at 15 years, $P=.01$ ), freedom from atrioventricular valve reoperation after total cavopulmonary connection ( $75 \%$ vs $99 \%$ at 15 years, $P<.01)$, and grade of atrioventricular valve regurgitation at a median follow-up of 6.6 years $(P<.01)$ were worse than in those who did not require atrioventricular valve surgery.

Conclusions: Atrioventricular valve regurgitation in univentricular heart is more frequently associated with a tricuspid or a common atrioventricular valve, and structural anomalies are the primary cause. Significant atrioventricular valve regurgitation requiring surgery influences survival after total cavopulmonary connection, especially when atrioventricular valve replacement was needed. Surgical management based on mechanisms of regurgitation is mandatory. ( $\mathrm{J}$ Thorac Cardiovasc Surg 2018;155:701-9)

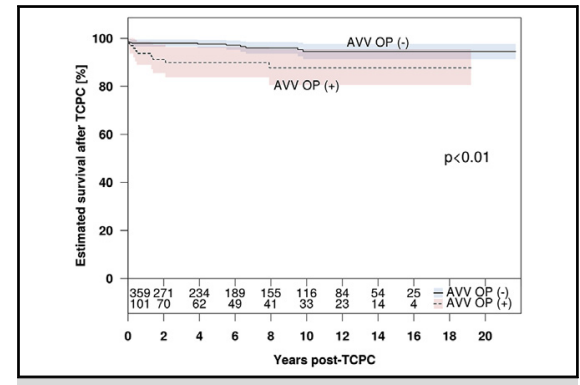

Freedom from death or transplantation after TCPC in patients with and without AW surgery.

\section{Central Message}

Morphologic anomalies are the primary cause of AVV regurgitation in functional singleventricle physiology. Surgical interventions influence survival after TCPC.

\section{Perspective}

Our results suggest that $22 \%$ of the patients required AVV surgery before or at TCPC and that most AVV regurgitation ( $88 \%$ ) was associated with structural valve abnormalities. Surgical intervention before or at TCPC had a negative impact on survival, AVV reoperation, and late AVV function. Although valve repair is the goal, results are not satisfactory and reoperation at the valve is high

See Editorial Commentary page 710

See Editorial page 700

\footnotetext{
From the Departments of ${ }^{\mathrm{a}}$ Cardiovascular Surgery and ${ }^{\mathrm{b}}$ Pediatric Cardiology and Congenital Heart Disease, German Heart Center Munich at the Technical University of Munich; ${ }^{c}$ Department of Congenital Heart Disease, Marie Lannelongue Hospital, Les Plessis-Robinson, France; and ${ }^{\mathrm{d}}$ German Centre for Cardiovascular Research, Munich, Germany.

${ }^{\dagger}$ Deceased.

This study was supported by grants from the Werner Reichenberger Foundation for Child Health.

Read at the 97th American Association for Thoracic Surgery, Boston, Massachusetts, April 29-May 3, 2017.
}

Received for publication Feb 5, 2017; revisions received June 30, 2017; accepted for publication Aug 26, 2017; available ahead of print Oct 6, 2017.

Address for reprints: Masamichi Ono, MD, PhD, Department of Cardiovascular Surgery, German Heart Center Munich at the Technical University of Munich, Lazarettstraße 36, 80636 Munich, Germany (E-mail: ono@dhm.mhn.de). $0022-5223 / \$ 36.00$

Copyright ( 2017 by The American Association for Thoracic Surgery https://doi.org/10.1016/j.jtcvs.2017.08.122 


\section{Abbreviations and Acronyms \\ $\mathrm{AVV}=$ atrioventricular valve \\ BCPS = bidirectional cavopulmonary shunt \\ $\mathrm{CAVV}=$ common atrioventricular valve \\ HLHS $=$ hypoplastic left heart syndrome \\ $\mathrm{MV}=$ mitral valve \\ TCPC $=$ total cavopulmonary connection \\ TEE $=$ transesophageal echocardiography \\ $\mathrm{TV}=$ tricuspid valve}

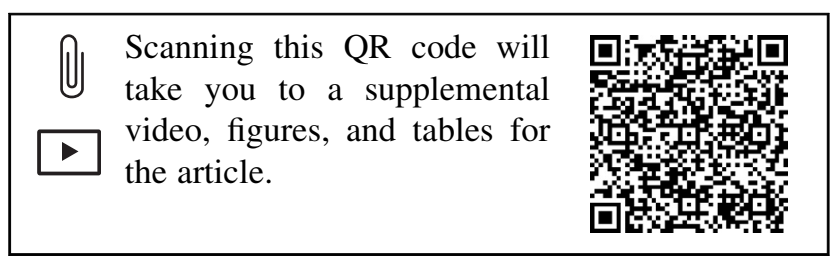

In patients with a functionally single ventricle, the staged Fontan palliation with a bidirectional cavopulmonary shunt (BCPS) and later a total cavopulmonary connection (TCPC) is currently a successful treatment concept. Significant atrioventricular valve (AVV) regurgitation can complicate the clinical course at any stage. In the early era of univentricular palliation, significant AVV regurgitation was a contraindication for performing the Fontan procedure. ${ }^{1}$ However, various modifications to the Fontan procedure, improved perioperative management, and the introduction and refinement of AVV repair techniques have improved the survival of patients with a functional single ventricle and AVV regurgitation during the past few decades. ${ }^{2-8}$ Despite such advances, recent studies have demonstrated that significant AVV regurgitation still poses a major risk for patients undergoing a staged Fontan palliation and is associated with systemic ventricular dysfunction and worse clinical outcomes. ${ }^{4,6-14}$

In patients with a single ventricle, AVV morphology can be complex, and the mechanisms for AVV regurgitation are often multifactorial. Various AVV repair techniques have been described, and advantages and disadvantages have been identified. ${ }^{3-8,15-18}$ Even so, the best timing is unknown and AVV repair is technically challenging. Few studies have focused on the influence of AVV regurgitation and AVV surgery on outcomes after TCPC. ${ }^{8}$ We investigated (1) which AVV morphology is most susceptible to AVV regurgitation and which mechanisms are involved; and (2) whether AVV regurgitation requiring surgical intervention influences survival, AVV operation rate, and ventricular and AVV function after TCPC.

\section{MATERIALS AND METHODS}

The Institutional Review Board of the Technical University of Munich approved this study. The medical records of all 705 patients who were surgically treated for staged single-ventricle palliation at the German Heart Center Munich between 1994 and 2015 were reviewed, and 460 patients who underwent TCPC were included in this study. Because the purpose of this study was to evaluate the impact of AVV regurgitation on outcomes after TCPC, the remaining 245 patients were excluded from this study, including 32 patients who underwent AVV surgery ( 8 patients before stage II and 24 patients at or after stage II). AVV was classified according to the modified congenital Heart Surgery Nomenclature and Database Project classification ${ }^{19}$ : single mitral valve (MV), single tricuspid valve (TV), 2 separate valves, and common AVV (CAVV) (single-orifice AVV associated with complete atrioventricular septal defect).

\section{Atrioventricular Valve Anatomy and Function}

$\mathrm{AVV}$ and ventricular morphology, as well as structural abnormalities of the AVV, were determined from echocardiographic reports. After AVV surgery, mechanisms of AVV regurgitation were based on the surgical reports. The extent of AVV regurgitation was classified as 0 (none), 1 (trivial), 2 (mild), 3 (moderate), or 4 (severe). Moderate or severe regurgitation was considered to represent significant AVV regurgitation. Systemic ventricular function and ventricular dilatation were evaluated by echocardiography. Ventricular function was graded by the investigator as normal (ejection fraction $>50 \%$ ), mildly reduced, moderately reduced, or severely reduced.

\section{Indication and Timing of Atrioventricular Valve Surgery}

Moderate AVV regurgitation was added to the staged surgery, and severe AVV regurgitation was addressed in a separate procedure between the staged procedures. Indications for AVV surgery were based on transthoracic echocardiography findings and confirmed by intraoperative transesophageal echocardiography (TEE). Usually, severe recurrent AVV regurgitation was treated as soon as it was detected, whereas moderate recurrent AVV regurgitation was addressed at the next stage of palliation.

\section{Operative Techniques}

AVV repair was performed under standard cardiopulmonary bypass with cardioplegic cardiac arrest. Surgical techniques were individualized according to the valve pathology reported from the echocardiographer. Intraoperatively, saline was injected into the ventricle to confirm the mechanism of AVV regurgitation. Attention was paid to the annular dimension, commissural leak, prolapse or restriction of the leaflets, and leaflet and subvalvular abnormalities. Local annuloplasty and commissuroplasty were the primary techniques for treating annular dilatation, leaflet prolapse, or both (Video 1).

Different types of annuloplasty were performed: usually, a 5-0 or 6-0 Prolene horizontal mattress suture was placed along the commissures where the predominant regurgitant jet was detected. Partial annuloplasty was performed in patients with prolapse of 1 or 2 leaflets, resulting in failure of coaptation. Circular annuloplasty was performed using the De Vega technique. An annuloplasty ring was used only in patients with an adultsize annulus.

Commissuroplasty was achieved with edge-to-edge approximation of the leaflet tissue using 6-0 or 7-0 Prolene sutures. Occasionally, the posterior leaflet of the TV was obliterated using the method of Ohye and colleagues. ${ }^{4}$ If localized or generalized prolapse occurred when the chordae and subvalvular apparatus of the adjacent leaflet were essentially normal, this was treated with edge-to-edge approximation of the commissures to attach the prolapsing region to the nonprolapsing region.

In patients with poor coaptation of 2 opposing leaflets, suturing of the free-floating segments of the opposing leaflets created double orifices, and edge-to-edge repair was performed. If a single cleft or dehiscence was the primary cause of regurgitation, it was primarily closed with interrupted Prolene sutures. If the valve leaflets were dysplastic and had 


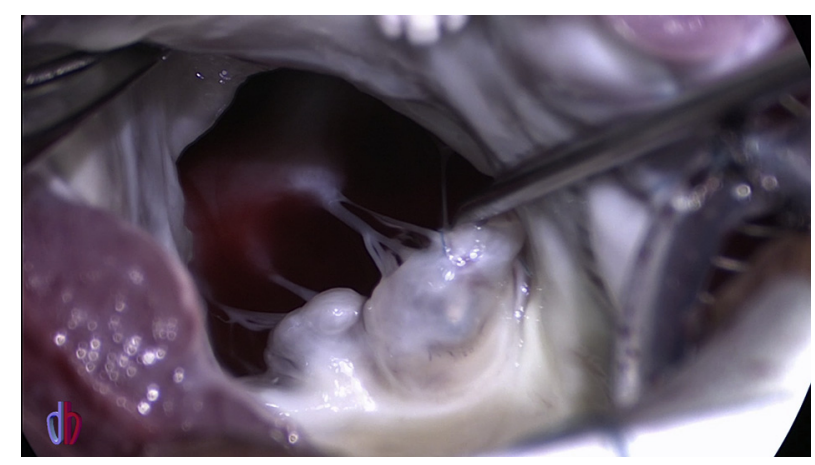

VIDEO 1. TV repair in patients with HLHS using combined techniques of partial annuloplasty, commissuroplasty, and leaflet adaptation. Video available at: http://www.jtcvsonline.org/article/S0022-5223(17)31897-4/fulltext.

complex dehiscence, a combination of valvuloplasty, commissuroplasty, and valve adaptation was performed.

Closure of an AVV with regurgitation was considered when the second AVV had a good function and appropriate size. If there was severe residual regurgitation or irreparable leaflet abnormalities, AVV replacement was performed using a standard bileaflet mechanical valve.

Intraoperative TEE was performed routinely. The repair was revised if residual regurgitation was moderate or severe.

\section{Outcome Assessment}

Patients were carefully and regularly (once per year for asymptomatic patients and twice or more for symptomatic patients) followed by pediatric cardiologists in an outpatient setting. Mortality, cause of death, and morbidity were regularly tracked using our institutional Fontan patient database system. The severity of AVV regurgitation and ventricular function were regularly evaluated with transthoracic echocardiography. The Kaplan-Meier method was used to estimate and compare the overall survival and AVV surgery-free survival.

\section{Identification of Factors Influencing Early and Late Outcomes}

Risk factors for death or transplantation and AVV surgery after TCPC were determined using Cox proportional hazards regression models. The patients' independent variables included morphologic and functional AVV characteristics listed in Table E1. Analysis of risk factors for ventricular dysfunction was performed using stepwise logistic regression analysis.

\section{Statistical Analysis}

Continuous variables were expressed as mean with standard deviation or median (interquartile range). An independent sample $t$ test was used to compare variables with a normal distribution, and the Wilcoxon rank-sum test was used for variables that were not normally distributed. The chisquare test was used for categoric data. Overall survival and AVV surgery-free survival after TCPC were estimated by the Kaplan-Meier method. Univariable analysis of the survival risk was performed by the log-rank test. For multivariable analysis, we used Cox proportional hazards regression to evaluate independent predictors of outcome events. Variables at least weakly associated with outcomes $(P<.1)$ in the univariable analysis were entered into the Cox regression models. The final models were derived by forward and backward stepwise selection. Hazard ratios were calculated with $95 \%$ confidence intervals. All analyses were performed with SPSS 20.0 for Windows (IBM, Ehningen, Germany).

\section{RESULTS}

\section{Atrioventricular Valve Morphology and Initial Atrioventricular Valve Surgery}

The patients' characteristics and type of AVV are shown in Table E2; 153 patients $(33 \%)$ presented with 2 separate valves, 108 patients $(24 \%)$ presented with a predominant MV, 155 patients (34\%) presented with a predominant TV, and 44 patients $(10 \%)$ presented with a CAVV. By the time of the Fontan completion (before or concurrent with TCPC), 101 of the 460 patients $(22 \%)$ had undergone AVV surgery, including $33(22 \%)$ of 153 patients with 2 separate valves, $11(10 \%)$ of 108 patients with a predominant MV, $41(27 \%)$ of 155 patients with a predominant TV, and $16(36 \%)$ of 44 patients with a CAVV (Table E3). Patients with a TV and CAVV underwent AVV surgery more frequently $(P<.001)$ than patients with a single MV. The median age at initial AVV surgery was 2 (0.8-4.0) years. Systemic ventricular function was normal in 83 patients $(82 \%)$ and reduced in 18 patients $(18 \%)$ at the time of their initial AVV surgery. The timing of 2 separate valves surgery relative to MV and TV surgery is shown in Table E4. In patients with 2 separate valves, surgery was more frequently performed on the TV. Patients' characteristics with and without AVV surgery are shown in Table 1.

\section{Primary Mechanisms, Initial Surgery, and Early Outcome}

The most common primary mechanism of AVV regurgitation was leaflet dysplasia $(n=62,61 \%)$, followed by leaflet prolapse $(\mathrm{n}=53,53 \%)$, annular dilatation $(\mathrm{n}=27,27 \%)$, and leaflet cleft $(\mathrm{n}=22,22 \%)$. Pure annular dilatation was documented in 12 patients $(12 \%)$, whereas 60 patients $(59 \%)$ had at least 2 major mechanisms of regurgitation. Dysplastic leaflet and prolapsed leaflet were observed most commonly in patients with 2 separate valves ( $\mathrm{n}=26,79 \%$, and $\mathrm{n}=24,73 \%$, respectively). Restrictive leaflets were primarily observed in patients with a TV $(\mathrm{n}=12,29 \%)$. Papillary muscle anomaly was seen in 3 patients with 2 separate valves and an MV (Table E3).

AVV reconstruction was performed in 81 patients $(80 \%)$, AVV closure in 16 patients $(16 \%)$, and AVV replacement in 4 patients $(4 \%)$. The techniques used were commissural approximation $(\mathrm{n}=50,50 \%)$, leaflet adaptation $(\mathrm{n}=49$, $49 \%$ ), and annuloplasty in 27 patients $(27 \%)$. After initial AVV repair, intraoperative TEE demonstrated no AVV regurgitation in 9 patients, trivial in 41 patients, mild in 25 patients, and moderate in 6 patients, whereas discharge echocardiography revealed no AVV regurgitation in 5 patients, trivial in 17 patients, mild in 37 patients, and moderate in 22 patients.

\section{Repeat Atrioventricular Valve Surgery}

A second AVV surgery was performed in 32 patients: A total of 22 patients underwent repeat AVV surgery before 
TABLE 1. Comparison of characteristics of patients with and without atrioventricular valve surgery

\begin{tabular}{|c|c|c|c|}
\hline Variables & $\frac{\text { AVV operation }(+)}{(n=101)}$ & $\frac{\text { AVV operation }(-)}{(n=359)}$ & $P$ value \\
\hline \multicolumn{4}{|l|}{ Patient characteristics } \\
\hline Age at TCPC (y) & $4.6 \pm 5.2$ & $3.8 \pm 4.1$ & .11 \\
\hline Weight at TCPC $(\mathrm{kg})$ & $16.7 \pm 11.9$ & $15.2 \pm 9.7$ & .25 \\
\hline Male & 51 & 238 & .004 \\
\hline HLHS & 29 & 81 & .201 \\
\hline $\mathrm{TA}$ & 5 & 66 & .001 \\
\hline DILV & 15 & 53 & .982 \\
\hline PAIVS & 4 & 20 & .520 \\
\hline Unbalanced CAVSD & 5 & 7 & .095 \\
\hline TGA & 42 & 143 & .751 \\
\hline DORV & 19 & 46 & .126 \\
\hline $\mathrm{CoA}$ & 13 & 50 & .785 \\
\hline Dextrocardia/situs inversus & 10 & 31 & .693 \\
\hline Heterotaxy & 11 & 26 & .234 \\
\hline Dominant right ventricle & 65 & 179 & .010 \\
\hline \multicolumn{4}{|l|}{ Palliation and pre-Fontan condition } \\
\hline Prior $\mathrm{PAB}$ & 26 & 48 & .003 \\
\hline Prior DKS/Norwood & 41 & 145 & .971 \\
\hline TAPCV/PAPVC & 10 & 21 & .151 \\
\hline Pacemaker placed before TCPC & 4 & 8 & .335 \\
\hline Loss of sinus rhythm before TCPC & 12 & 31 & .322 \\
\hline \multicolumn{4}{|l|}{ Pre-TCPC catheter data } \\
\hline Mean PAP (mm Hg) & $10.2 \pm 3.4$ & $9.3 \pm 3.0$ & .019 \\
\hline Mean LAP (mm Hg) & $6.1 \pm 2.9$ & $5.3 \pm 2.2$ & .007 \\
\hline TPG $(\mathrm{mm} \mathrm{Hg})$ & $3.8 \pm 2.1$ & $3.8 \pm 2.0$ & .89 \\
\hline Systolic SV pressure $(\mathrm{mm} \mathrm{Hg})$ & $81.1 \pm 11.1$ & $82.7 \pm 14.0$ & .34 \\
\hline $\operatorname{SVEDP}(\mathrm{mm} \mathrm{Hg})$ & $7.7 \pm 3.1$ & $7.3 \pm 2.8$ & .31 \\
\hline Systolic pressure of the aorta $(\mathrm{mm} \mathrm{Hg})$ & $78.3 \pm 12.6$ & $80.0 \pm 14.0$ & .30 \\
\hline Mean pressure of the aorta $(\mathrm{mm} \mathrm{Hg})$ & $55.9 \pm 9.6$ & $57.1 \pm 11.2$ & .37 \\
\hline Aortic SO2 (\%) & $82.3 \pm 5.1$ & $82.6 \pm 5.4$ & .66 \\
\hline
\end{tabular}

Significant values are in bold. $A V V$, Atrioventricular valve; $T C P C$, total cavopulmonary connection; $H L H S$, hypoplastic left heart syndrome; $T A$, tricuspid atresia; $D I L V$, double inlet left ventricle; PAIVS, pulmonary atresia with intact ventricular septum; CAVSD, complete atrioventricular septum defect; TGA, transposition of the great arteries; DORV, double outlet right ventricle; $C O A$, coarctation of the aorta; $P A B$, pulmonary artery banding; $D K S$, Damus-Kaye-Stansel anastomosis; TAPVC, total anomalous pulmonary venous connection; $P A P V C$, partial anomalous pulmonary venous connection; $P A P$, pulmonary artery pressure; $T P G$, transpulmonary gradient; $S V$, systemic ventricle; $S V E D P$, systemic ventricle end diastolic pressure; $L A P$, left atrium pressure; $S O 2$, oxygen saturation.

(6) or concurrent with (16) the Fontan completion, at a median time of $1.2(0.1-4.7)$ years after the initial AVV surgery (Figure E1). Repeat repair was performed in 17 patients, AVV replacement was performed in 4 patients, and AVV closure was performed in 1 patient. Among the 17 patients with a repeat repair, postprocedural regurgitation was absent or trivial in 5 patients, mild in 6 patients, and moderate in 6 patients. Ten patients underwent repeat AVV surgery after TCPC ( 8 after repair and 2 after replacement). Three patients underwent repeat AVV repair, whereas 5 received an AVV replacement and 2 required an AVV closure. The secondary mechanisms of regurgitation are shown in Table E5.

A third AVV surgery was required in 6 patients; 5 patients needed AVV replacement, and 1 patient underwent a third successful AVV repair, followed by TCPC 14 months later. Finally, the AVV was replaced with a mechanical prosthesis in 14 patients, the AVV was closed in 19 patients, and the repaired AVV remained functional in 68 patients.

Risk factors that were at least weakly associated with AVV reoperation and AVV replacement $(P<.1)$ in the univariable analysis are listed in Table 2 . The following factors were significant predictors in the multivariable analysis: Prolapse predicted AVV reoperation, and chordal anomaly predicted AVV replacement.

Among 359 patients who underwent TCPC but did not require AVV surgery, 1 patient with 2 separate valves developed significant tricuspid regurgitation 9 years after TCPC and underwent TV closure.

\section{Influence of Atrioventricular Valve Surgery on Perioperative Outcomes at Total Cavopulmonary Connection}

There were 8 deaths $(1.7 \%)$ within 30 days after TCPC ( 3 patients with previous/concomitant AVV surgery and 5 
TABLE 2. Risk factors for atrioventricular valve reoperation and atrioventricular valve replacement

\begin{tabular}{|c|c|c|c|c|c|c|}
\hline \multirow[b]{2}{*}{ Risk factor } & \multicolumn{3}{|c|}{ Univariable model } & \multicolumn{3}{|c|}{ Multivariable Model } \\
\hline & HR & OR $(95 \%$ CI $)$ & $P$ value & HR & OR $(95 \%$ CI $)$ & $P$ value \\
\hline \multicolumn{7}{|c|}{ AVV reoperation $(30 / 81)^{*}$} \\
\hline Prolapse & 2.755 & $1.292-5.872$ & .009 & 2.755 & $1.292-5.872$ & .009 \\
\hline Chordal anomaly & 2.154 & $0.918-5.053$ & .078 & & & \\
\hline PM anomaly & 6.188 & $0.799-43.950$ & .081 & & & \\
\hline \multicolumn{7}{|c|}{ AVV replacement (14/101) } \\
\hline Annular dilatation & 2.598 & $0.868-7.778$ & .088 & & & \\
\hline Prolapse & 2.799 & $0.915-8.558$ & .071 & & & \\
\hline Restrictive leaflet & 4.756 & $1.184-19.101$ & .028 & & & \\
\hline Chordal anomaly & 9.482 & $3.195-28.139$ & $<.001$ & 9.482 & $3.195-28.139$ & $<.001$ \\
\hline PM anomaly & 11.030 & $1.227-99.158$ & .032 & & & \\
\hline
\end{tabular}

$H R$, Hazard ratio; $O R$, odds ratio; $C I$, confidence interval; $A V V$, atrioventricular valve; $P M$, papillary muscle. $*$ Patient with initial AVV repair.

patients without AVV surgery; $P=.382)$. At the time of initial AVV repair for the 81 patients, in 44 who required AVV surgery at the time of TCPC and 37 who required AVV surgery before TCPC, we found differences in the incidence of ascites, incidence of chylothorax, and degree of AVV regurgitation at discharge between the groups (Table 3).

TABLE 3. Outcomes after total cavopulmonary connection in patients undergoing initial atrioventricular valve repair $(\mathbf{n}=81)$

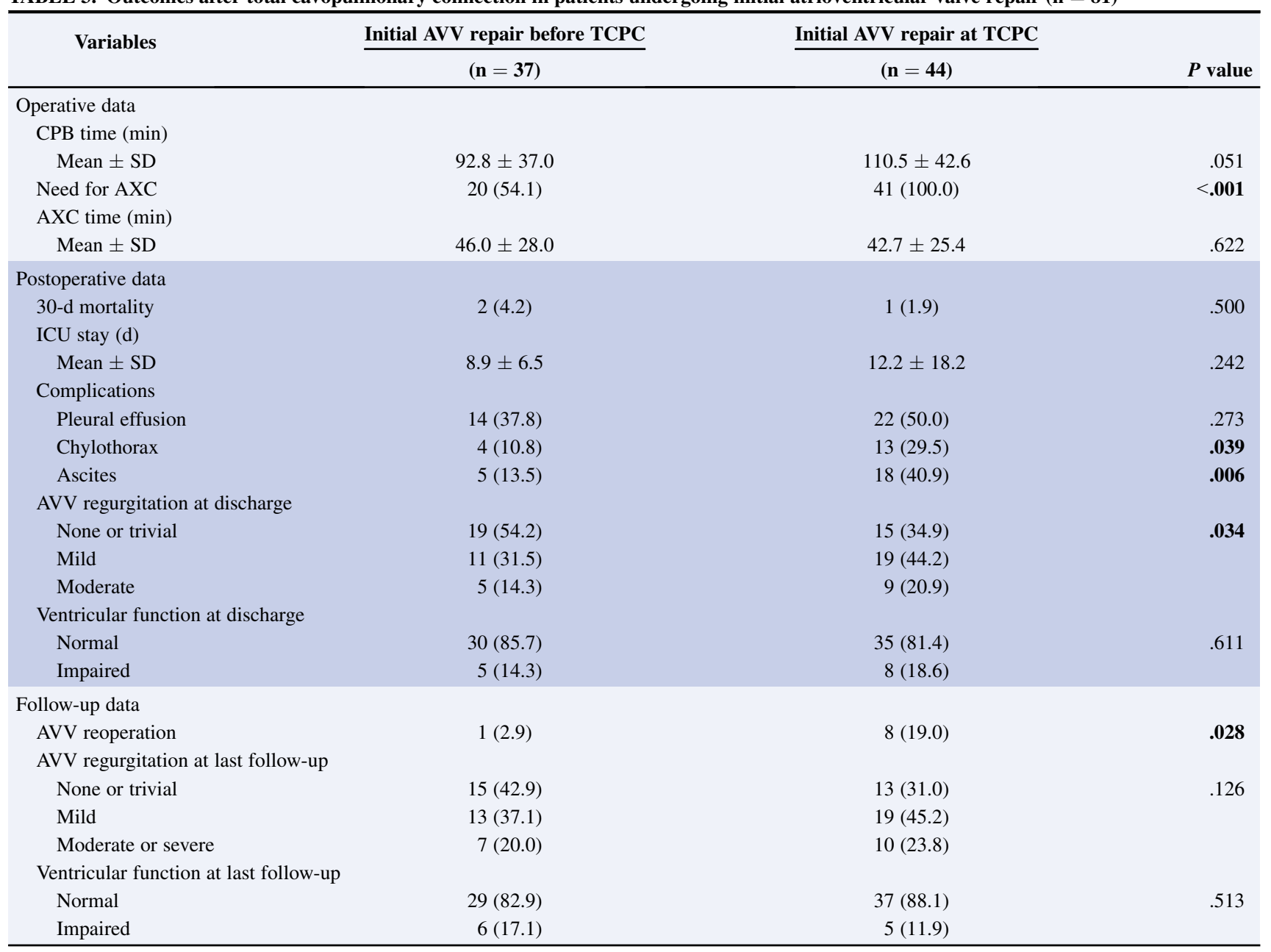

Significant values are in bold. Variables were presented in $\mathrm{N}(\%)$ or mean $\pm \mathrm{SD}$. $A V V$, Atrioventricular valve; $T C P C$, total cavopulmonary connection; $C P B$, cardiopulmonary bypass; $S D$, standard deviation; $A X C$, aortic crossclamp; $I C U$, intensive care unit. 


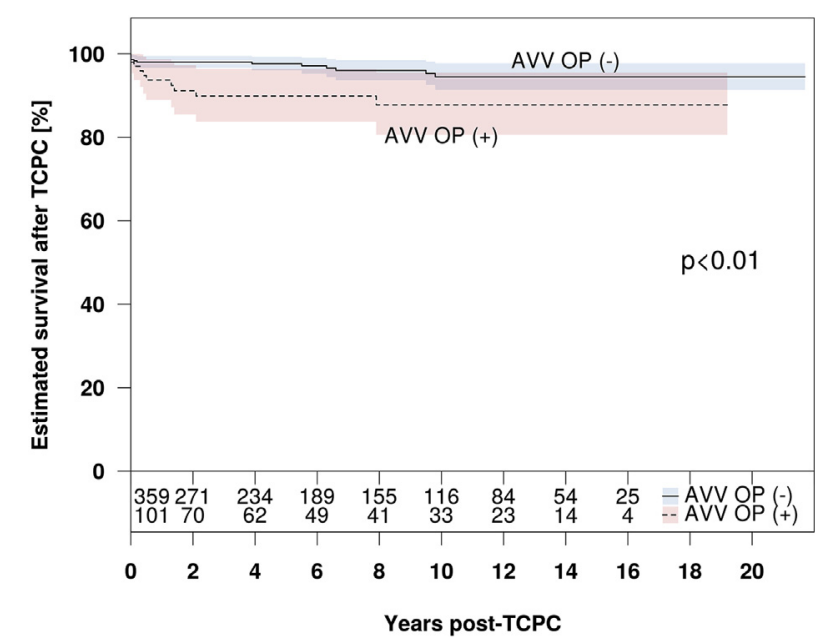

FIGURE 1. Kaplan-Meier estimates of overall survival. AVV $O P$, Atrioventricular valve operation; $T C P C$, total cavopulmonary connection.

\section{Influence of Atrioventricular Valve Surgery on Late Outcomes After Total Cavopulmonary Connection}

Among 452 early survivors, 10 patients were lost to follow-up. The median follow-up period was 6.6 (2.311.7) years in the remaining 442 patients. There were 14 late deaths (9 patients with previous/concomitant AVV surgery and 5 patients without AVV surgery). The 101 patients requiring AVV surgery had a lower overall survival than patients without AVV surgery ( 88 vs $95 \%$ at 15 years, $P=.01$ ) (Figure 1). Freedom from AVV reoperation after TCPC was lower in patients undergoing AVV surgery before or concurrent with TCPC than in patients without AVV surgery before or concurrent with TCPC $(75 \%$ vs $99 \%$ at 15 year, $P<.001$ ) (Figure E2).

Among the 101 patients requiring AVV surgery, the estimated overall survival was significantly shorter for those

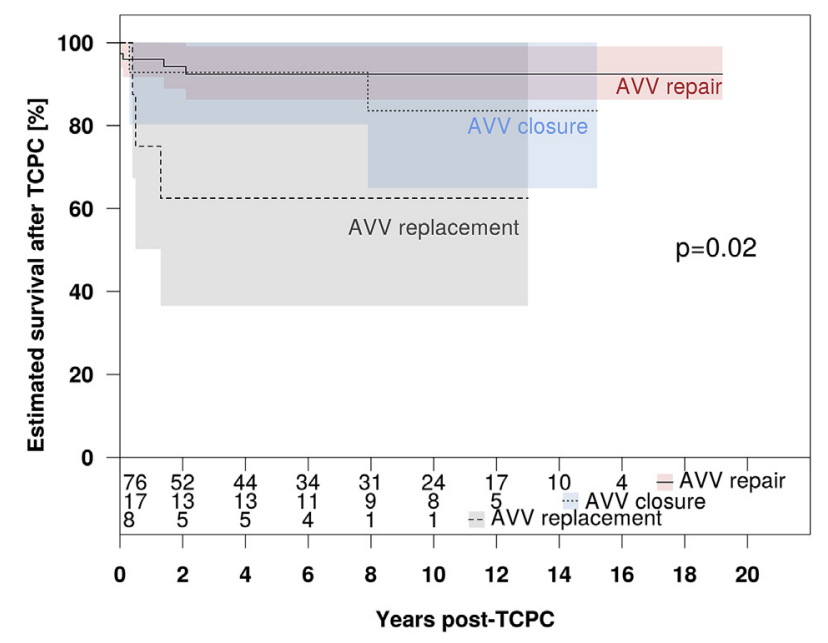

FIGURE 2. Kaplan-Meier estimates of overall survival according to surgical procedure. $A V V$, Atrioventricular valve; $T C P C$, total cavopulmonary connection. who underwent replacement $(P=.02$, Figure 2$)$ than for those who underwent repair or closure. However, no difference in freedom from AVV reoperation was found $(P=.07$, Figure E3) among those who underwent repair, closure, or replacement. Freedom from AVV reoperation after TCPC was lower in patients who demonstrated post-TCPC ventricular dysfunction than those who did not $(P=.033)$ (Figure 3), whereas no significant difference was observed between the patients with and without pre-TCPC ventricular dysfunction $(P=.188)$.

Fifteen patients, who exhibited moderate or more AVV regurgitation after AVV surgery upon TCPC, had a higher incidence of late AVV surgery $(P=.005)$, higher degree of AVV regurgitation $(P<.001)$, and more often reduced ventricular function $(P=.018)$ at last follow-up compared with 86 patients who had no or only mild AVV regurgitation after AVV surgery upon TCPC. There was no significant difference in overall survival after TCPC between the groups $(P=.571)$.

Risk factors that were at least weakly associated with mortality and morbidity after TCPC $(P<.1)$ in the univariable analysis are listed in Table 4 . The following factors were significant predictors in the multivariable analysis: Papillary muscle anomaly and cleft closure predicted mortality, and chordal anomaly and post-TCPC AVV regurgitation predicted AVV reoperation.

\section{Atrioventricular Valve Regurgitation and Ventricular Function at Last Follow-up}

Systemic ventricular function and AVV regurgitation were abstracted from the last available echocardiographic reports $(n=442$, median of 6.6 [2.3-11.7] years postoperatively). Among 95 patients who underwent AVV surgery, the final echocardiographic AVV regurgitation was none in 25 patients $(26 \%)$, trivial in 13 patients $(14 \%)$, mild in 45 patients $(47 \%)$, and moderate in 12 patients $(13 \%)$. The grade of AVV regurgitation was significantly less in patients without AVV surgery: none in $126(36 \%)$, trivial in $134(39 \%)$, mild in $78(22 \%)$, and moderate in $9(3 \%)$ $(P<.001)$. Ventricular function at last follow-up after AVV surgery was normal in 84 patients $(88 \%)$, mildly reduced in 7 patients $(7 \%)$, and moderately reduced in 4 patients $(4 \%)$; the distribution of these categories of ventricular function did not differ significantly from those of patients without AVV surgery. The results of the risk factor analysis for ventricular dysfunction are shown in Table E6.

\section{DISCUSSION}

The key findings of the present study were as follows: (1) Twenty-two percent of the patients required at least $1 \mathrm{AVV}$ surgery before or concurrent with their TCPC. (2) Patients with a morphologic TV or CAVV had a higher rate of significant AVV regurgitation. (3) Most AVV regurgitation $(88 \%)$ was associated with structural valve abnormalities. (4) Annular dilation was significantly associated with 


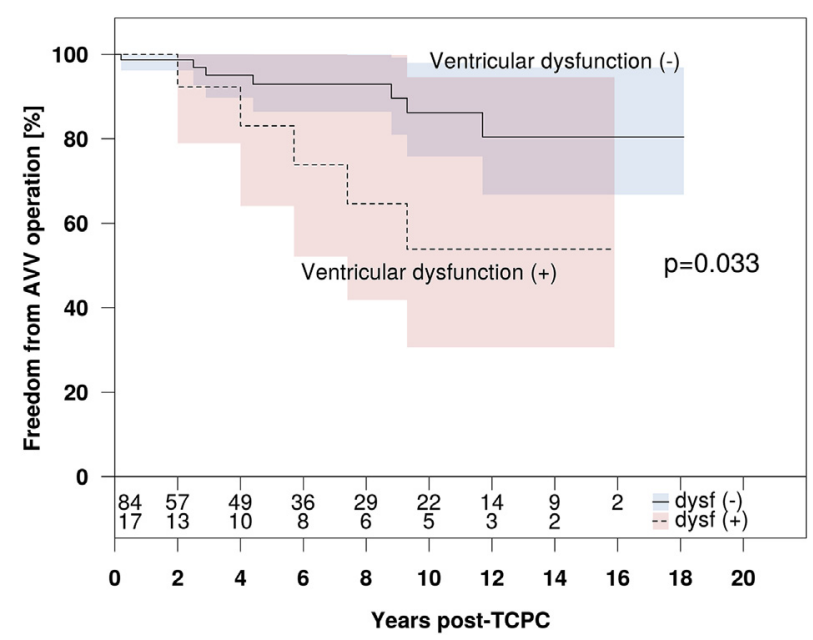

FIGURE 3. Kaplan-Meier estimates of freedom from AVV operation according to post-TCPC ventricular function. $A V V$, Atrioventricular valve; $T C P C$, total cavopulmonary connection.

systemic ventricular dysfunction. (5) AVV regurgitation requiring surgical intervention before or concurrent with TCPC had a negative impact on survival, AVV reoperation, and late AVV function.

\section{Atrioventricular Valve Morphology and Mechanisms of Atrioventricular Valve Regurgitation}

Honjo and colleagues ${ }^{6}$ stated that in patients with a single ventricle undergoing AVV repair, most AVV regurgitation $(85 \%)$ was related to anatomic abnormalities of the leaflets or subvalvular apparatus, with the remainder $(15 \%)$ due to pure annular dilatation. In our series, 12 patients $(12 \%)$ had pure annular dilation and 89 patients $(88 \%)$ had anatomic abnormalities. In the present study, AVV regurgitation was more frequent in patients with TV and CAVV than in those with a morphologic MV. These findings have been confirmed by others ${ }^{16,17}$ and may be due to the fact that structural anomalies are more likely to be associated with $\mathrm{TV}^{20}$ and $\mathrm{CAVV}^{21}$

In addition to structural abnormalities, annular dilatation caused by shunt-dependent physiology is an important cause of AVV regurgitation during the stage of "parallel" circulation before stage II volume-unloading surgery.
Chronic volume overload due to a systemic-topulmonary shunt and aortopulmonary collateral arteries can cause progressive ventricular dilatation followed by annular dilatation. Other potential reasons for annular dilatation may be myocardial ischemia, coronary malperfusion, and systemic ventricular outflow tract obstruction. It was reported that annular dilatation is strongly correlated with postrepair ventricular dysfunction and impaired survival. ${ }^{6,22,23}$ In the present study, a strong correlation between annular dilatation and systemic ventricular dysfunction was found, but annular dilatation did not influence survival after TCPC.

\section{Atrioventricular Valve Surgery, Durability, and Reoperation}

Valve repair is the first choice for AVV regurgitation and results in measurable improvement of valve function. However, in this study, 30 of 81 patients $(37 \%)$ required reoperation at a median of $1.2(0.1-4.7)$ years after initial AVV surgery. Ando and Takahashi ${ }^{24}$ reported that 19 of 93 patients $(20 \%)$ required repeat AVV procedures, and Wong and associates ${ }^{7}$ reported that 20 of 76 patients $(26 \%)$ required repeat AVV repair or valve replacement at a median of 2.8 years. The high incidence of reoperations is due to structural anomalies of the AVV. Especially, anomaly of the subvalvular apparatus such as papillary muscle anomaly or chordae anomaly was associated with worse outcomes after initial repair in risk factor analysis of this study. AVV closure is an option when the other AVV is appropriately sized. In our series, 17 patients underwent AVV closure, and no patient needed further AVV operation. Thus, in this situation, early closure of an AVV with regurgitation is a good alternative. AVV replacement remains the final option. However, survival after TCPC was significantly shorter after AVV replacement than after AVV reconstruction or closure.

\section{Tricuspid Valve Repair in Patients With a Single Right Ventricle}

The TV is more likely to fail as a systemic AVV, and there is a high incidence of major structural abnormalities in

TABLE 4. Risk factors for mortality and morbidity after total cavopulmonary connection

\begin{tabular}{|c|c|c|c|c|c|c|}
\hline \multirow[b]{2}{*}{ Risk factor } & \multicolumn{3}{|c|}{ Univariable model } & \multicolumn{3}{|c|}{ Multivariable Model } \\
\hline & HR & OR $(95 \%$ CI $)$ & $P$ value & HR & OR $(95 \% \mathrm{CI})$ & $P$ value \\
\hline \multicolumn{7}{|l|}{ Mortality after TCPC $(10 / 101)$} \\
\hline PM anomaly & 13.062 & $2.720-62.715$ & .001 & 15.994 & $3.134-81.608$ & .001 \\
\hline Cleft closure & 3.278 & $0.923-11.645$ & .066 & 3.809 & $1.032-14.058$ & .045 \\
\hline \multicolumn{7}{|c|}{ AVV reoperation after TCPC $(12 / 101)$} \\
\hline Chordal anomaly & 6.254 & $1.930-20.261$ & .002 & 6.243 & $1.839-21.197$ & .003 \\
\hline AVV regurgitation post-TCPC & 4.536 & $1.420-14.491$ & .011 & 4.470 & $1.339-14.926$ & .015 \\
\hline
\end{tabular}

$O R$, Odds ratio; $H R$, hazard ratio; $C I$, confidence interval; $T C P C$, total cavopulmonary connection; $P M$, papillary muscle; $A V V$, atrioventricular valve. 
patients with hypoplastic left heart syndrome (HLHS).$^{20}$ In this series, TV repair required multiple techniques, such as posterior leaflet obliteration, bicuspidalization, and more complex strategies (commissuroplasty, chordal shortening, edge-to-edge repair, and other leaflet reapproximation techniques). A restrictive septal leaflet is difficult to manage. Recently, we have performed patch augmentation of the septal leaflet with bovine pericardium, achieving improved leaflet coaptation; however, further assessment of the longterm outcome is required. In our study, structural abnormalities of the TV were often accompanied by a high incidence of annular dilation and ventricular dysfunction in patients with a single right ventricle. Long-term function of the right ventricle in patients with Fontan circulation has been shown to be comparable to left ventricular function; however, TV anomalies and the need for AVV surgery require special attention in patients with a single right ventricle. ${ }^{25-28}$

\section{Atrioventricular Valve Regurgitation and Systemic Ventricular Function}

Many studies have demonstrated that the development of AVV regurgitation and systemic ventricular dysfunction are closely related. ${ }^{3,4,6,8,22}$ However, the direction of the relationship is not fully understood, because AVV regurgitation may be the cause or the result of ventricular dysfunction. In 1997, Imai and colleagues ${ }^{3}$ reported a large series of patients undergoing AVV repair concurrent with the Fontan procedure. They found that postoperative ventricular dysfunction was unpredictable and a risk factor for late death. The authors hypothesized that the decreased afterload produced by AVV regurgitation progressively induces ventricular dilatation without appropriate hypertrophy, resulting in a dilated ventricle with relatively thin walls. The sudden increase of afterload after AVV repair may lead to a breakdown of systemic ventricular function. For patients with HLHS, Ohye and associates ${ }^{4}$ found that early tricuspid repair in the presence of preserved right ventricular function yielded good long-term results. However, if repair was performed in the presence of impaired ventricular function, progressive postrepair ventricular dysfunction could cause redilatation of the AVV annulus. ${ }^{4}$ Honjo and colleagues ${ }^{6}$ analyzed 57 patients with functional single-ventricle physiology undergoing AVV repair. The authors concluded that worse ventricular function and ventricular dilatation at the time of repair were correlated with death and procedural failure. ${ }^{6}$ Pinsky and colleagues ${ }^{29}$ reported that chronic volume-related ventricular dysfunction may not be consistently reversible after AVV surgery. We found that the presence of ventricular dysfunction at TCPC did not increase subsequent mortality. Our results also demonstrated that annular and ventricular dilatation were associated with systemic ventricular dysfunction. Thus, preventing annular dilatation is critical to preserving ventricular and AVV function. Chronic volume overload- related ventricular dysfunction may not be reversible after AVV surgery, and AVV regurgitation is unlikely to respond to volume-unloading surgery alone $\mathrm{e}^{30-32}$; therefore, to prevent further annular dilatation and preserve or improve ventricular function, it might be preferable to widen the indications for annuloplasty at stage II (BCPS), or even at stage I (Norwood), ${ }^{33}$ in patients with severe annular dilatation and moderate AVV regurgitation.

\section{Timing of Atrioventricular Valve Surgery: Before or at the Time of Total Cavopulmonary Connection}

Several reports suggested the benefit of early AVV intervention in patients with single ventricles. ${ }^{6,33,34}$ Early AVV repair before TCPC could prevent the breakdown of systemic ventricular function at the time of Fontan completion as Imai and colleagues ${ }^{3}$ reported. We compared the postoperative outcomes of patients who received AVV repair at the time of TCPC and before TCPC. Accordingly, there were less postoperative complications and less degree of postoperative AVV regurgitation in patients who received AVV surgery before TCPC. Because previous studies demonstrated prolonged stay is associated with postdischarge morbidities, ${ }^{14,35}$ performing TCPC as a sole therapy seems to be important, and our results supported the rationale for early AVV repair before TCPC. Our institutional policy to address moderate AVV regurgitation has gradually been changed to perform AVV repair as a sole operation before TCPC. In a recent case in this study, AVV repair was performed concomitant with and after BCPS 3 times before TCPC. The postoperative course after TCPC was uneventful in this patient. Further investigation is needed to clarify whether this is a good practice.

\section{Study Limitations}

This was a retrospective, nonrandomized, single-center study. Mechanisms of AVV anomalies were inferred from the operation records, and bias among surgeons can be expected. Because of the small size of some subgroups, results should be interpreted cautiously because only large effects could be identified. Finally, surgical and medical management may have changed during the study period, possibly influencing the long-term results. The limited number of outcome events might limit the reliability of the Cox regression results in some cases (end points).

\section{CONCLUSIONS}

AVV regurgitation requiring surgical intervention was more frequently associated with the TV and CAVV than the MV. Most AVV regurgitation was related to anatomic abnormalities. AVV surgery improved the grade of regurgitation. However, there is a high incidence of reoperation after AVV repair. AVV regurgitation requiring surgical intervention before or concurrent with TCPC negatively 
affects survival and AVV function after TCPC. Annular dilatation at initial AVV surgery was an independent predictor of postoperative ventricular dysfunction. Because AVV structural abnormalities are intrinsic mechanisms of AVV regurgitation and annular dilatation is highly associated with ventricular dysfunction, AVV repair should be considered on the basis of the mechanisms for regurgitation. Early intervention could improve outcomes in patients with a functional single ventricle undergoing staged Fontan completion.

\section{Conflict of Interest Statement}

Authors have nothing to disclose with regard to commercial support.

\section{References}

1. Choussat A, Fontan F, Besse O. Selection criteria for Fontan's procedure. In: Anderson RH, Shinebourne EA, eds. Pediatric Cardiology. Edinburgh: Churchill Livingstone; 1978:559-66.

2. Vargas FJ, Mayer JE Jr, Jonas RA, Castaneda AR. Atrioventricular valve repair or replacement in atriopulmonary anastomosis: surgical considerations. Ann Thorac Surg. 1987;43:403-5.

3. Imai Y, Takanashi Y, Hoshino S, Terada M, Aoki M, Ohta J. Modified Fontan procedure in ninety-nine cases of atrioventricular valve regurgitation. J Thorac Cardiovasc Surg. 1997;113:262-8.

4. Ohye RG, Gomez CA, Goldberg CS, Graves HL, Devaney EJ, Bove EL. Tricuspid valve repair in hypoplastic left heart syndrome. J Thorac Cardiovasc Surg. 2004; 127:465-72.

5. Ando M, Takahashi Y. Edge-to-edge repair of common atrioventricular or tricuspid valve in patients with functionally single ventricle. Ann Thorac Surg. 2007:84:1571-6.

6. Honjo O, Atlin CR, Mertens L, Al-Radi OO, Redington AN, Caldarone $\mathrm{CA}$, et al. Atrioventricular valve repair in patients with functional single-ventricle physiology: impact of ventricular and valve function and morphology on survival and reintervention. J Thorac Cardiovasc Surg. 2011;142:326-35.

7. Wong DJ, Iyengar AJ, Wheaton GR, Ramsay JM, Grigg LE, Horton S, et al. Long-term outcomes after atrioventricular valve operations in patients undergoing single-ventricle palliation. Ann Thorac Surg. 2012;94:606-13.

8. Liu VJ, Yong MS, d'Udekem Y, Weintraub RG, Praporski S, Brizard CP, et al. Outcomes of atrioventricular valve operation in patients with Fontan circulation. Ann Thorac Surg. 2015;99:1632-8.

9. Ono M, Boethig D, Goerler H, Lange M, Westhoff-Bleck M, Breymann T. Clinical outcome of patients 20 years after Fontan operation-effect of fenestration on late morbidity. Eur J Cardiothorac Surg. 2006;30:923-9.

10. Hirsch JC, Goldberg C, Bove EL, Salehian S, Lee T, Ohye RG, et al. Fontan operation in the current era: a 15-year single institution experience. Ann Surg. 2008; 248:402-10.

11. Anderson PA, Sleeper LA, Mahony L, Colan SD, Atz AM, Breitbart RE, et al; Pediatric Heart Network Investigators. Contemporary outcomes after the Fontan procedure: a Pediatric Heart Network multicenter study. J Am Coll Cardiol. 2008; 52:85-98.

12. d'Udekem Y, Iyengar AJ, Cochrane AD, Grigg LE, Ramsay JM, Wheaton GR, et al. The Fontan procedure: contemporary techniques have improved longterm outcomes. Circulation. 2007;116(11 Suppl):I157-64.

13. Nakano T, Kado H, Tatewaki H, Hinokiyama K, Oda S, Ushinohama H, et al. Results of extracardiac conduit total cavopulmonary connection in 500 patients. Eur J Cardiothorac Surg. 2015;48:825-32.

14. Ono M, Kasnar-Samprec J, Hager A, Cleuziou J, Burri M, Langenbach C, et al. Clinical outcome following total cavopulmonary connection: a 20-year single center experience. Eur J Cardiothorac Surg. 2016;50:632-41.
15. Honjo O, Mertens L, Van Arsdell GS. Atrioventricular valve repair in patients with single-ventricle physiology: mechanisms, techniques of repair, and clinical out comes. Semin Thorac Cardiovasc Surg Pediatr Card Surg Annu. 2011;14:75-84.

16. Ota N, Fujimoto Y, Murata M, Tosaka Y, Ide Y, Tachi M, et al. Improving outcomes of the surgical management of right atrial isomerism. Ann Thorac Surg. 2012:93:832-8.

17. Kotani Y, Chetan D, Atlin CR, Mertens LL, Jegatheeswaran A, Caldarone CA, et al. Longevity and durability of atrioventricular valve repair in singleventricle patients. Ann Thorac Surg. 2012;94:2061-9.

18. Mahle WT, Gaynor JW, Spray TL. Atrioventricular valve replacement in patients with a single ventricle. Ann Thorac Surg. 2001;72:182-6.

19. Jacobs ML, Mayer JE Jr. Congenital Heart Surgery Nomenclature and Database Project: single ventricle. Ann Thorac Surg. 2000;69(4 Suppl):S197-204.

20. Stamm C, Anderson RH, Ho SY. The morphologically tricuspid valve in hypoplastic left heart syndrome. Eur J Cardiothorac Surg. 1997;12:587-92.

21. Vijarnsorn C, Khoo NS, Tham EB, Colen T, Rebeyka IM, Smallhorn JF. Increased common atrioventricular valve tenting is a risk factor for progression to severe regurgitation in patients with a single ventricle with unbalanced atrioventricular septal defect. J Thorac Cardiovasc Surg. 2014;148:2580-8.

22. Chetan D, Kotani Y, Jacques F, Poynter JA, Benson LN, Lee KJ, et al. Surgical palliation strategy does not affect interstage ventricular dysfunction or atrioventricular valve regurgitation in children with hypoplastic left heart syndrome and variants. Circulation. 2013;128:S205-12.

23. Jang WS, Kim WH, Choi K, Lee JR, Kim YJ, Kwon BS, et al. What factors predict long-term survival and valve durability in patients with atrioventricular valve regurgitation in single-ventricle physiology? Pediatr Cardiol. 2013;34:1366-73.

24. Ando M, Takahashi Y. Long-term functional analysis of the atrioventricular valve in patients undergoing single ventricle palliation. Ann Thorac Surg. 2011;92: $1767-73$.

25. d'Udekem Y, Xu MY, Galati JC, Lu S, Iyengar AJ, Konstantinov IE, et al. Predictors of survival after single-ventricle palliation: the impact of right ventricular dominance. J Am Coll Cardiol. 2012;59:1178-85.

26. Khairy P, Fernandes SM, Mayer JE Jr, Triedman JK, Walsh EP, Lock JE, et al Long-term survival, modes of death, and predictors of mortality in patients with Fontan surgery. Circulation. 2008;117:85-92.

27. Ohuchi H, Yasuda K, Hasegawa S, Miyazaki A, Takamuro M, Yamada O, et al Influence of ventricular morphology on aerobic exercise capacity in patients after the Fontan operation. J Am Coll Cardiol. 2001;37:1967-74.

28. Sano T, Ogawa M, Yabuuchi H, Matsuda H, Nakano S, Shimazaki Y, et al. Quantitative cineangiographic analysis of ventricular volume and mass in patients with single ventricle: relation to ventricular morphologies. Circulation. 1988;77:62-9.

29. Pinsky WW, Lewis RM, Hartley CJ, Entman ML. Permanent changes of ventricular contractility and compliance in chronic volume overload. Am J Physiol. 1979;237:H575-83.

30. Kasnar-Samprec J, Kühn A, Hörer J, Vogt M, Cleuziou J, Lange R, et al. Unloading of right ventricle by bidirectional superior cavopulmonary anastomosis in hypoplastic left heart syndrome patients promotes remodeling of systemic right ventricle but does not improve tricuspid regurgitation. J Thorac Cardiovasc Surg. 2012;144:1102-8.

31. Yamagishi S, Masuoka A, Uno Y, Katogi T, Suzuki T. Influence of bidirectional cavopulmonary anastomosis and concomitant valve repair on atrioventricular valve annulus and function. Ann Thorac Surg. 2014;98:641-7.

32. Mahle WT, Cohen MS, Spray TL, Rychik J. Atrioventricular valve regurgitation in patients with single ventricle: impact of the bidirectional cavopulmonary anastomosis. Ann Thorac Surg. 2001;72:831-5.

33. Huang SC, Chen YS, Chang CI, Chiu IS. Outcome of tricuspid valve plasty in Norwood stage I operation. Circ J. 2016;80:1362-70.

34. Kwak JG, Park CS, Lee CH, Lee C, Kim SJ, Song JY, et al. Early surgical correction of atrioventricular valvular regurgitation in single-ventricle patients. Ann Thorac Surg. 2010;90:1320-3.

35. Mori M, McCracken C, Maher K, Kogon B, Mahle W, Kanter K, et al. Outcomes of neonates requiring prolonged stay in the intensive care unit after surgical repair of congenital heart disease. J Thorac Cardiovasc Surg. 2016;152:720-7.

Key Words: atrioventricular valve regurgitation, congenital, Fontan procedure, functional single ventricle, heart defects 


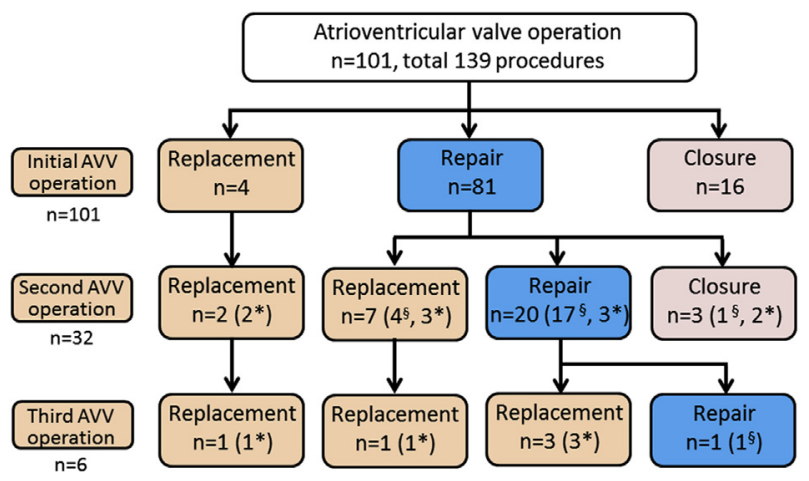

FIGURE E1. Distribution of AVV operations. §The number of operations performed before or concurrent with TCPC. *The number of operations performed after TCPC. $A V V$, Atrioventricular valve.

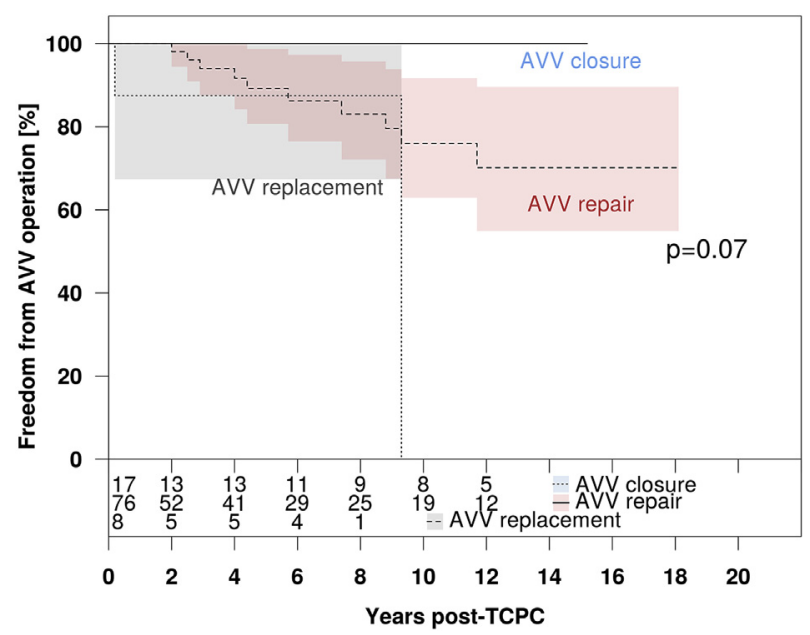

FIGURE E3. Kaplan-Meier estimates of freedom from AVV operation according to surgical procedure. $A V V$, Atrioventricular valve; $T C P C$, total cavopulmonary connection.

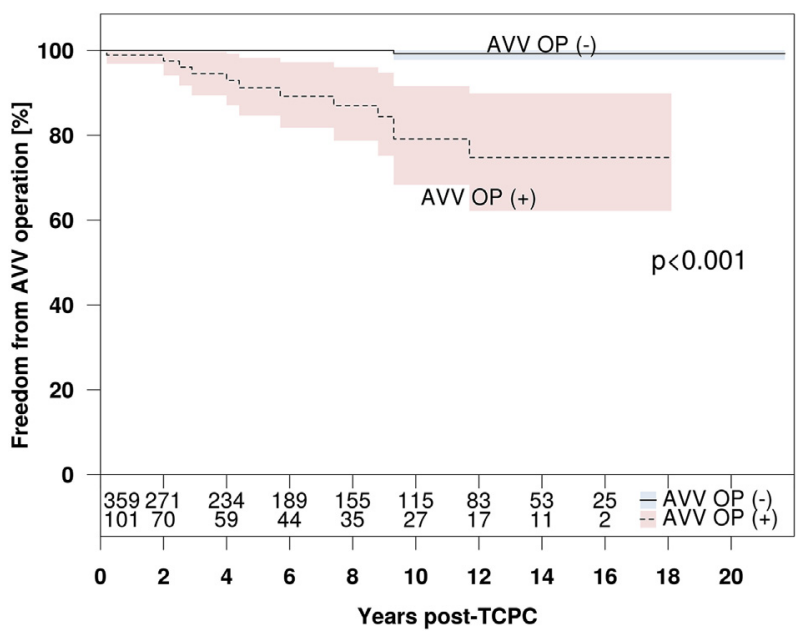

FIGURE E2. Kaplan-Meier estimates of freedom from AVV operation. $A V V O P$, Atrioventricular valve operation; TCPC, total cavopulmonary connection. 
TABLE E1. Variables used for risk factor analysis

\begin{tabular}{l} 
Variables \\
\hline AVV morphology and function \\
AVV morphology \\
2 separate valves \\
MV \\
TV \\
CAVV \\
AVV regurgitation before initial AVV surgery \\
AVV regurgitation after initial AVV surgery \\
AVV regurgitation post-TCPC \\
Ventricular morphology and function \\
Dominant right ventricle \\
Reduced ventricular function at TCPC \\
Timing of initial AVV surgery \\
Before TCPC \\
At TCPC \\
Valve pathology \\
Annular dilatation \\
Dysplastic leaflet \\
Prolapse \\
Cleft \\
Restrictive leaflet \\
Tethering \\
Chordal anomaly \\
Papillary muscle anomaly \\
Valve procedure \\
Annuloplasty \\
Leaflet adaptation \\
Cleft closure \\
Alfieri stitch \\
Commissural approximation \\
No. of AVV surgeries* \\
AVV, Atrioventricular valve; $M V$, mitral valve; $T V$, tricuspid valve; $C A V V$, common \\
atrioventricular valve; $T C P C$, total cavopulmonary connection. *Only used for late \\
venicular dysfunction.
\end{tabular}


TABLE E2. Patient characteristics and atrioventricular valve morphology

\begin{tabular}{|c|c|c|c|c|c|}
\hline & All & 2 separate valves & MV & TV & CAVV \\
\hline $\mathrm{N}(\%)$ & 460 & $153(33.3)$ & $108(23.5)$ & $155(33.7)$ & $44(9.6)$ \\
\hline \multirow[t]{3}{*}{ Diagnosis } & HLHS: 105 & DILV: 65 & TA: 74 & HLHS: 105 & Heterotaxy: 24 \\
\hline & TA: 74 & ccTGA: 19 & PAIVS: 24 & MA: 28 & CAVSD: 11 \\
\hline & DILV: 65 & DIRV: 7 & Ebstein: 2 & & \\
\hline Male sex & $289(62.8)$ & $88(57.5)$ & $63(58.3)$ & $111(71.6)$ & $27(61.4)$ \\
\hline TGA & $185(40.2)$ & $113(73.9)$ & $25(23.1)$ & $24(15.5)$ & $23(52.3)$ \\
\hline $\mathrm{CoA}$ & $63(13.7)$ & $31(20.3)$ & $12(11.1)$ & $16(10.3)$ & $4(9.1)$ \\
\hline Dextrocardia & $41(8.9)$ & $15(9.8)$ & $4(3.7)$ & $7(4.5)$ & $15(34.1)$ \\
\hline Heterotaxy & $37(8.0)$ & $6(3.9)$ & $1(0.9)$ & $6(3.9)$ & $24(54.5)$ \\
\hline $\mathrm{RV}$ dominant SV & $244(53.0)$ & $55(35.9)$ & $0(0)$ & $155(100)$ & $34(77.3)$ \\
\hline РАB & $74(16.1)$ & $40(26.1)$ & $6(5.6)$ & $17(11.0)$ & $11(25.0)$ \\
\hline Norwood/DKS & $186(40.4)$ & $46(30.1)$ & $17(15.7)$ & $119(76.8)$ & $4(9.1)$ \\
\hline TAPVC & $31(6.7)$ & $2(1.3)$ & $1(0.9)$ & $9(5.8)$ & $19(43.2)$ \\
\hline Aortopulmonary shunt & $136(29.6)$ & $53(34.6)$ & $51(47.2)$ & $20(12.9)$ & $12(27.3)$ \\
\hline Blalock-Taussig shunt & $135(29.3)$ & $43(28.1)$ & $36(33.3)$ & $43(27.7)$ & $13(29.5)$ \\
\hline Sano shunt & $79(17.2)$ & $6(3.9)$ & $1(0.9)$ & $69(44.5)$ & $3(6.8)$ \\
\hline PCPC & $411(89.3)$ & $124(81.0)$ & $97(89.8)$ & $151(97.4)$ & 39 (88.6) \\
\hline Fenestration & $35(7.6)$ & $16(10.5)$ & $8(7.4)$ & $7(4.5)$ & $4(9.1)$ \\
\hline Age at TCPC & $2.3(1.8-4.0)$ & $2.5(1.9-5.5)$ & $2.2(1.7-3.4)$ & $2.2(1.7-3.4)$ & $2.5(1.9-4.4)$ \\
\hline Weight at TCPC & $12(10-15)$ & $12(10-19)$ & $12(11-14)$ & $12(11-14)$ & $12(10-14)$ \\
\hline Height at TCPC & $88(83-101)$ & $89(85-117)$ & $88(82-96)$ & $88(82-96)$ & $89(82-102)$ \\
\hline \multicolumn{6}{|l|}{ Pre-TCPC AVVR } \\
\hline 0 & $230(50.0)$ & $76(49.7)$ & $71(65.7)$ & $73(47.1)$ & $10(22.7)$ \\
\hline 1 & $117(25.4)$ & $39(25.5)$ & $29(26.9)$ & $35(22.6)$ & $14(31.8)$ \\
\hline 2 & $66(14.3)$ & $22(14.4)$ & $2(1.5)$ & $31(20.0)$ & $11(25.0)$ \\
\hline 3 & $45(9.8)$ & $16(10.5)$ & $5(4.6)$ & $16(10.3)$ & 8 (18.2) \\
\hline 4 & $2(0.4)$ & & $1(0.9)$ & & $1(2.3)$ \\
\hline \multicolumn{6}{|l|}{ Pre-TCPC SVF } \\
\hline Normal & $426(92.6)$ & $145(94.8)$ & $105(97.2)$ & $136(87.7)$ & $40(90.9)$ \\
\hline Mildly reduced & $27(5.9)$ & $7(4.6)$ & $1(0.9)$ & $15(9.7)$ & $4(9.1)$ \\
\hline Moderately reduced & $6(1.3)$ & $1(0.7)$ & $2(1.9)$ & $3(1.9)$ & \\
\hline Severely reduced & $1(0.2)$ & & & $1(0.6)$ & \\
\hline
\end{tabular}


TABLE E3. Timing, mechanisms, and surgical technique of initial atrioventricular valve operation

\begin{tabular}{|c|c|c|c|c|c|c|}
\hline & Overall & $2 \mathrm{AVV}$ & MV & TV & CAVV & $P$ value \\
\hline Patient No. $(\%)$ & $101(22.0)$ & $33(21.6)$ & $11(10.2)$ & $41(26.5)$ & $16(36.4)$ & $<.001$ \\
\hline \multicolumn{7}{|l|}{ Time of first AVV surgery } \\
\hline At stage I & $3(3.0)$ & $1(3.0)$ & & $1(2.4)$ & $1(6.3)$ & \\
\hline Between stage I and II & $7(6.9)$ & $3(9.1)$ & $3(27.3)$ & $1(2.4)$ & & \\
\hline Stage II (PCPC) & $35(34.7)$ & $13(39.4)$ & $3(27.3)$ & $11(26.8)$ & $8(50.0)$ & \\
\hline Between stage II and III & $3(3.0)$ & & & $3(7.3)$ & & \\
\hline Stage III (TCPC) & $53(52.5)$ & $16(48.5)$ & $5(45.5)$ & $25(61.0)$ & $7(43.8)$ & \\
\hline Total & $101(100)$ & $33(100)$ & $11(100)$ & $41(100)$ & $16(100)$ & \\
\hline Age at first AVV surgery & $2.0(0.8-4.0)$ & $2.0(0.9-4.7)$ & $3.7(0.4-6.5)$ & $2.2(0.7-4.0)$ & $1.7(0.9-2.6)$ & .477 \\
\hline \multicolumn{7}{|c|}{ SV function at first AVV surgery } \\
\hline Normal & $83(82.2)$ & $31(93.9)$ & $11(100)$ & $26(63.4)$ & $15(93.8)$ & .001 \\
\hline Reduced & $18(17.8)$ & $2(6.1)$ & $0(0.0)$ & 15 (36.6) & $1(6.3)$ & \\
\hline ECC time & $104.9 \pm 37.0$ & $97.4 \pm 39.6$ & $107.7 \pm 41.7$ & $110.6 \pm 35.8$ & $105.6 \pm 31.6$ & .588 \\
\hline AXC time & $40.3 \pm 26.2$ & $40.6 \pm 29.0$ & $50.0 \pm 30.3$ & $36.0 \pm 24.1$ & $42.6 \pm 21.9$ & .521 \\
\hline \multicolumn{7}{|l|}{ Primary pathology } \\
\hline Annular dilatation & $27(26.7)$ & $6(18.2)$ & $1(9.1)$ & $16(39.0)$ & $4(25.0)$ & .104 \\
\hline \multicolumn{7}{|l|}{ Leaflet } \\
\hline Dysplastic & $62(61.4)$ & $26(78.8)$ & $6(54.5)$ & $26(63.4)$ & $4(25.0)$ & .004 \\
\hline Prolapse & $53(52.5)$ & $24(72.7)$ & $5(45.5)$ & $19(46.3)$ & $5(31.3)$ & .027 \\
\hline Cleft & $22(21.8)$ & $5(15.2)$ & $4(36.4)$ & $7(17.1)$ & $6(37.5)$ & .166 \\
\hline Restrictive leaflet & $13(12.9)$ & $0(0.0)$ & $1(9.1)$ & $12(29.3)$ & $0(0.0)$ & .001 \\
\hline Tethering & $2(2.0)$ & $0(0.0)$ & $1(9.1)$ & $1(2.4)$ & $0(0.0)$ & .272 \\
\hline Chordal anomaly & $14(13.9)$ & $3(9.1)$ & $2(18.2)$ & $7(17.1)$ & $2(12.5)$ & .758 \\
\hline Papillary muscle anomaly & $3(3.0)$ & $2(6.1)$ & $1(9.1)$ & $0(0.0)$ & $0(0.0)$ & .234 \\
\hline \multicolumn{7}{|l|}{ Initial surgical technique } \\
\hline Valve repair & $81(80.2)$ & $24(72.3)$ & $5(45.5)$ & $36(87.8)$ & $16(100)$ & \\
\hline \multicolumn{7}{|l|}{ Annuloplasty } \\
\hline DeVega & 14 (13.9) & $4(12.1)$ & $0(0.0)$ & $7(17.1)$ & $3(18.8)$ & .470 \\
\hline Partial annuloplasty & $10(9.9)$ & $1(3.0)$ & $1(9.1)$ & $7(17.1)$ & $1(6.3)$ & .225 \\
\hline Artificial ring & $3(3.0)$ & $1(3.0)$ & $0(0.0)$ & $2(4.9)$ & $0(0.0)$ & .719 \\
\hline \multicolumn{7}{|l|}{ Valve reconstruction } \\
\hline Leaflet adaptation & $49(48.5)$ & $18(54.5)$ & $1(9.1)$ & $20(48.8)$ & $10(62.5)$ & .035 \\
\hline Cleft closure & $20(19.8)$ & $6(18.2)$ & $3(27.3)$ & $7(17.1)$ & $4(25.0)$ & .824 \\
\hline Alfieri stitch & $7(6.9)$ & $2(6.1)$ & $1(9.1)$ & $4(9.8)$ & $0(0.0)$ & .611 \\
\hline $\begin{array}{l}\text { Commissural } \\
\text { approximation }\end{array}$ & $50(49.5)$ & $18(54.5)$ & $2(18.2)$ & $24(58.5)$ & $6(37.5)$ & .075 \\
\hline Valve closure & $16(15.8)$ & $9(27.3)$ & $5(45.5)$ & $2(4.9)$ & $0(0.0)$ & \\
\hline Direct & 7 (6.9) & $5(15.2)$ & $1(9.1)$ & $1(2.4)$ & $0(0.0)$ & \\
\hline Patch & $9(8.9)$ & $4(12.1)$ & $4(36.4)$ & $1(2.4)$ & $0(0.0)$ & \\
\hline Valve replacement & $4(4.0)$ & $0(0.0)$ & $1(9.1)$ & $3(7.3)$ & $0(0.0)$ & \\
\hline
\end{tabular}

$\overline{A V V}$, Atrioventricular valve; $M V$, mitral valve; $T V$, tricuspid valve; $C A V V$, common atrioventricular valve; $P C P C$, partial cavopulmonary connection; $T C P C$, total cavopulmonary connection; $S V$, systemic ventricle; $E C C$, extracardiopulmonary circulation; $A X C$, aortic crossclamp. 
TABLE E4. Atrioventricular valve surgery in patients with 2 separate valves

\begin{tabular}{lcccc}
\hline & MV & TV & (Total) \\
\hline At stage I & 1 & 0 & 1 \\
Between stage I and II & 2 & 1 & 3 \\
Stage II (PCPC) & 3 & 11 & $13(1)^{*}$ \\
Between stage II and III & 0 & 0 & 0 \\
Stage III (TCPC) & 4 & 13 & $16(1)^{*}$ \\
Total & 10 & 25 & $33(35)$ \\
\hline
\end{tabular}

$M V$, Mitral valve; $T V$, tricuspid valve; $P C P C$, partial cavopulmonary connection; $T C P C$, total cavopulmonary connection. *Patient underwent both MV and TV procedure concomitantly.

TABLE E5. Timing, mechanisms, and surgical technique of second atrioventricular valve operation

\begin{tabular}{|c|c|c|c|c|c|}
\hline & Overall & $2 \mathrm{AVV}$ & MV & TV & CAVV \\
\hline $\mathrm{N}(\%)$ & $32(31.7)$ & $9(27.3)$ & $3(27.3)$ & $12(29.3)$ & $8(50.0)$ \\
\hline \multicolumn{6}{|l|}{ Timing of second AVV surgery } \\
\hline Before TCPC & $6(18.8)$ & $2(22.2)$ & $1(33.3)$ & $2(16.7)$ & $1(12.5)$ \\
\hline At TCPC & $16(50.0)$ & $5(55.6)$ & $0(0.0)$ & $6(50.0)$ & $5(62.5)$ \\
\hline Post-TCPC & $10(31.3)$ & $2(22.2)$ & $2(66.7)$ & $4(33.3)$ & $2(25.0)$ \\
\hline \multicolumn{6}{|l|}{ Secondary pathology } \\
\hline Annular dilatation & $10(31.3)$ & $3(33.3)$ & & $4(33.3)$ & $3(37.5)$ \\
\hline \multicolumn{6}{|l|}{ Leaflet } \\
\hline Dysplastic & $21(65.6)$ & $7(77.8)$ & $1(33.3)$ & $7(58.3)$ & $6(75.0)$ \\
\hline Prolapse & $6(18.8)$ & & $1(33.3)$ & $3(25.0)$ & $2(25.0)$ \\
\hline Cleft & $2(6.3)$ & $1(11.1)$ & $1(33.3)$ & & \\
\hline Restrictive leaflet & $5(15.6)$ & & & $5(41.7)$ & \\
\hline Chordae anomaly & $4(12.5)$ & $1(11.1)$ & & $2(16.7)$ & $1(12.5)$ \\
\hline Papillary muscle anomaly & $1(3.1)$ & & & $1(8.3)$ & \\
\hline Stenosis of prosthesis & $1(3.1)$ & & $1(33.3)$ & & \\
\hline Thrombus in prosthesis & $1(3.1)$ & & & $1(8.3)$ & \\
\hline \multicolumn{6}{|l|}{ Second surgical technique } \\
\hline Valve repair & $20(62.5)$ & $4(44.4)$ & $2(66.7)$ & $7(58.3)$ & $7(87.5)$ \\
\hline \multicolumn{6}{|l|}{ Annuloplasty } \\
\hline DeVega & $1(3.1)$ & & & $1(8.3)$ & \\
\hline Partial annuloplasty & $4(12.5)$ & $1(11.1)$ & & $1(8.3)$ & $2(25.0)$ \\
\hline Artificial ring & $1(3.1)$ & & & $1(8.3)$ & \\
\hline \multicolumn{6}{|l|}{ Valve reconstruction } \\
\hline Leaflet adaptation & $13(40.6)$ & $4(44.4)$ & $1(33.3)$ & $4(33.3)$ & $4(50.0)$ \\
\hline Cleft closure & $2(6.3)$ & $1(11.1)$ & $1(33.3)$ & & \\
\hline Alfieri stitch & $2(6.3)$ & & & & $2(25.0)$ \\
\hline Patch augmentation & $2(6.3)$ & & & $2(16.7)$ & \\
\hline $\begin{array}{l}\text { Commissural } \\
\text { approximation }\end{array}$ & $11(34.4)$ & $4(44.4)$ & $1(33.3)$ & $3(25.0)$ & $3(37.5)$ \\
\hline Valve closure & $3(9.4)$ & $3(33.3)$ & & & \\
\hline Direct & $2(6.3)$ & $2(22.2)$ & & & \\
\hline Patch & $1(3.1)$ & $1(11.1)$ & & & \\
\hline Valve replacement & $9(28.1)$ & $2(22.2)$ & $1(33.3)$ & $5(41.7)$ & $1(12.5)$ \\
\hline
\end{tabular}

$A V V$, Atrioventricular valve; $M V$, mitral valve; $T V$, tricuspid valve; $C A V V$, Common atrioventricular valve; $T C P C$, total cavopulmonary connection. 
TABLE E6. Risk factors for reduced systemic ventricular dysfunction

\begin{tabular}{|c|c|c|c|c|c|c|}
\hline \multirow[b]{3}{*}{ Risk factor } & \multicolumn{3}{|c|}{ Univariable model } & \multicolumn{3}{|c|}{ Multivariable model } \\
\hline & \multirow[b]{2}{*}{ OR } & \multirow{2}{*}{$\frac{\text { OR }}{(95 \% \mathrm{CI})}$} & \multirow[b]{2}{*}{$P$ value } & \multirow[b]{2}{*}{ OR } & \multirow{2}{*}{$\frac{\text { OR }}{(95 \% \mathrm{CI})}$} & \multirow[b]{2}{*}{$P$ value } \\
\hline & & & & & & \\
\hline \multicolumn{7}{|c|}{ Ventricular function before TCPC } \\
\hline Annular dilatation & 20.581 & $2.538-166.900$ & .005 & 19.020 & 2.303-157.106 & .006 \\
\hline $\begin{array}{l}\text { Systemic ventricular } \\
\text { dilatation }\end{array}$ & 12.115 & $2.482-59.140$ & .002 & & & \\
\hline Prolapse & 0.260 & $0.066-1.025$ & .054 & & & \\
\hline TV & 5.344 & $1.349-21.167$ & .017 & & & \\
\hline $2 \mathrm{AVV}$ & 6.175 & $0.762-50.048$ & .088 & & & \\
\hline Annuloplasty & 7.368 & $2.002-27.116$ & .003 & & & \\
\hline Leaflet adaptation & 0.179 & $0.037-0.863$ & .032 & & & \\
\hline \multicolumn{7}{|c|}{ Ventricular function at discharge after TCPC } \\
\hline Annular dilatation & 9.333 & $2.469-35.282$ & .001 & & & \\
\hline $\begin{array}{l}\text { Systemic ventricular } \\
\text { dilatation }\end{array}$ & 8.716 & $2.566-29.609$ & .001 & 4.301 & $1.100-16.825$ & .036 \\
\hline Prolapse & 0.333 & $0.108-1.034$ & .057 & & & \\
\hline TV & 9.333 & $2.469-35.282$ & .001 & 4.641 & $1.059-20.343$ & .042 \\
\hline $2 \mathrm{AVV}$ & 4.183 & $0.893-19.584$ & .069 & & & \\
\hline Annuloplasty & 5.378 & $1.783-10.222$ & .003 & & & \\
\hline \multicolumn{7}{|c|}{ Ventricular function at last follow-up } \\
\hline Annular dilatation & 4.121 & $1.019-16.667$ & .047 & & & \\
\hline $\begin{array}{l}\text { Systemic ventricular } \\
\text { dilatation }\end{array}$ & 3.500 & $0.945-12.966$ & .061 & & & \\
\hline No. of AVV operations & 3.006 & $1.221-7.402$ & .017 & 2.957 & $1.155-7.572$ & .024 \\
\hline $\begin{array}{l}\text { Post-TCPC AVV } \\
\text { regurgitation }\end{array}$ & 4.229 & $1.048-17.057$ & .043 & & & \\
\hline Chordal anomaly & 4.762 & $1.163-19.498$ & .030 & & & \\
\hline Annuloplasty & 3.600 & $0.995-13.019$ & .051 & & & \\
\hline
\end{tabular}

$O R$, Odds ratio; $C I$, confidence interval; $T C P C$, total cavopulmonary connection; $T V$, tricuspid valve; $A V V$, atrioventricular valve. 